\title{
Intercommunication between the Neuroendocrine and Immune Systems: Focus on Myasthenia Gravis
}

\author{
Jacqueline Mays ${ }^{\mathrm{a}}$ Cherié L. Butts ${ }^{\mathrm{b}}$ \\ a Laboratory of Viral Diseases, National Institute of Allergy and Infectious Diseases/National Institutes of Health, \\ and ${ }^{b}$ Laboratory of Immunology, Division of Therapeutic Proteins, Office of Biotechnology Products, Center for \\ Drug Evaluation and Research, US Food and Drug Administration, Bethesda, Md., USA
}

\section{Key Words}

Autoimmunity - Thymoma - Acetylcholine receptor •

Steroid hormones $\cdot$ Immune system

\begin{abstract}
Crosstalk exists between the nervous, endocrine, and immune systems, and perturbations in these interactions have been associated with disease. This includes production of neuroendocrine factors that alter immune system activity and increase susceptibility to or severity of immune-related conditions, such as myasthenia gravis (MG) - a T-cell-dependent, B-cell-mediated autoimmune disorder. MG results from impairment of transmission to the neuromuscular junction and involves the thymus - especially in early-onset disease, but the exact mechanism by which the thymus impacts disease is unclear. MG afflicts millions of individuals worldwide each year, and both men and women can develop symptoms. However, prevalence and age of onset differs between men and women. Women exhibit higher incidence and earlier age of onset compared to men, and disease fluctuates during pregnancy. This suggests that sex hormones play a role in influencing disease outcome. In this
\end{abstract}

review, we will consider what is known about the manifestation of MG, theories on how different forms of MG are influenced or alleviated by steroid hormones, current treatment options, and what measures could be important to consider in the future.

Copyright $\odot 2011$ S. Karger AG, Basel

\section{Introduction}

Myasthenia gravis (MG) is an autoimmune disorder that results in muscle weakness due to T-cell-dependent, antibody-mediated deterioration of the neuromuscular junction (NMJ). Antibodies generated during MG can be directed against muscle acetylcholine receptors (AChR), muscle-specific receptor tyrosine kinases (MuSK), or the muscles themselves. Women tend to have greater incidence and exhibit symptoms at a younger age; however, incidence is higher in men when MG is diagnosed much later in life [1]. Although biologically heterogeneous, disease is generally categorized as paraneoplastic or nonparaneoplastic [2] (table 1). In this review, we will discuss what is known about triggering events that initiate $M G$,

\section{KARGER}

Fax +41613061234 E-Mail karger@karger.ch www.karger.com
(C) 2011 S. Karger AG, Base

$1021-7401 / 11 / 0185-0320 \$ 38.00 / 0$

Accessible online at:

www.karger.com/nim
Cherie Butts, Laboratory of Immunology, Division of Therapeutic Proteins

Office of Biotechnology Products, Center for Drug Evaluation and Research

US Food and Drug Administration, 8800 Rockville Pike (HFD-122)

Building 29A, Room 3B19, Bethesda, MD 20892 (USA)

Tel. +1 301827 1843, E-Mail cherie.butts@fda.hhs.gov 
Table 1. Clinical manifestations of MG

\begin{tabular}{lll}
\hline Type of disease & Paraneoplastic & Nonparaneoplastic \\
\hline Age of onset & $<40$ years of age & $>40$ years of age \\
\hline Gender differences & Incidence higher in females & Incidence higher in males \\
\hline Status of thymus & Hyperplasia, neoplasia & Normal, atrophic \\
\hline Autoantibodies involved & Primarily AChR but also MuSK & AChR, MuSK, striated muscle proteins (titin, ryanodine) \\
\hline
\end{tabular}

involvement of the thymus, and what future strategies should be considered for therapies aimed at alleviating this debilitating condition.

\section{Forms of Disease}

Symptoms of MG include dropping eyelids and double vision from weakness of eye muscles (class I); difficulties chewing, swallowing, speech, and nasal tone and problems with muscles around the mouth; inability to hold objects, write, walk, stand, or climb stairs from problems with arm and leg muscles; and difficulty breathing due to problems with respiratory muscles (classes II-V, depending on severity). Muscles of the heart and intestine are generally not severely impacted. Symptoms vary between patients and tend to fluctuate under different circumstances (i.e., better with pregnancy, worse after delivery), although there are distinguishable features between the 2 major forms of MG.

Most patients with paraneoplastic MG are female and have early-onset MG (prior to age 40) that is characterized by anti-AChR antibodies and thymomas with lymphocytic infiltrates and germinal centers containing $\mathrm{T}$ cells, B cells, and plasma cells (reviewed in [3]). It is believed that thymomas develop from dysregulation of lymphocyte selection and presentation of self-antigens by neoplastic epithelial cells. In MG, thymomas usually express AChR-like epitopes and have many autoreactive T cells, which are thought to be positively selected for survival and exported to the periphery where they activate $B$ cells that produce antibodies - including those against AChR. Negative selection and regulation of autoreactive $T$ cells could be impaired in thymomas due to a deficiency in expression of the autoimmune regulator gene (AIRE) as well as loss of regulatory $\mathrm{T}$ cells $\left(\mathrm{T}_{\text {reg }}\right)$ [4]. Typical nonparaneoplastic MG patients are male and exhibit symptoms later in life ( $>40$ years) [5]. These individuals differ from paraneoplastic MG patients because they usually have a normal or atrophic thymus and rarely develop thymomas. They also have a wider variety of autoantibody repertoire, which includes antibodies against $\mathrm{AChR}$, MuSK, and the striated muscle proteins titin and ryanodine [6].

\section{Risk Factors}

Several factors have been correlated with disease onset including hormonal status, as evidenced by disease alteration during pregnancy and postparturition [7-9], and genetic predisposition [6]. Whatever the initiating events, they lead to dysregulated $\mathrm{T}$ cell activity and subsequent autoantibody production [10]. Polymorphisms in some immune-related and nonimmune-related genes are associated with increased susceptibility to MG. These include genes for the major histocompatibility complex (MHC) class II molecule human leukocyte antigen DR (HLA$D R$ ), the $\alpha$-subunit of AChR (CHRNA1), and the master autoimmune regulator (AIRE). MHC expression on antigen-presenting cells - such as monocytes, B cells, and dendritic cells - provides antigen that is necessary to stimulate T lymphocytes. Upon activation, T cells proliferate, secrete cytokines, and target cells expressing their cognate antigen for elimination. Other MHC genes have also been associated with increased susceptibility to $\mathrm{MG}$, such as the class II gene $H L A-D Q[11,12]$ and class I gene HLA-A [13]. Non-HLA genes have also been associated with increased risk. One of the most frequently identified is CHRNA1, which is the gene that encodes the $\alpha$-subunit of the AChR. Certain polymorphisms of CHRNA1 have been linked to altered expression in the thymus and subsequent breakdown of tolerance to AChR [14]. It is not clear whether dysregulated AChR expression on a specific cell type in the thymus - epithelial, thymocyte, or myoid cell - is critical for inducing disease. Another gene associated with increased susceptibility to MG is AIRE. Under normal conditions, T cells undergo negative selection in the thymic medulla to delete autoreactive $\mathrm{T}$ cells prior to their release into the periphery. Medullary thymic epithelial cells express several hundred different selfantigens (MHC, tissue-restricted antigens, etc.) under the 
Fig. 1. Schematic of thymus involvement in the development of MG. Tolerance to AChR is normally induced by deleting AChR-specific T cells in the thymus before they enter the periphery. In MG patients, tolerance is lost and results in the development of antibodies against AChR and other proteins involved in NMJ activity.

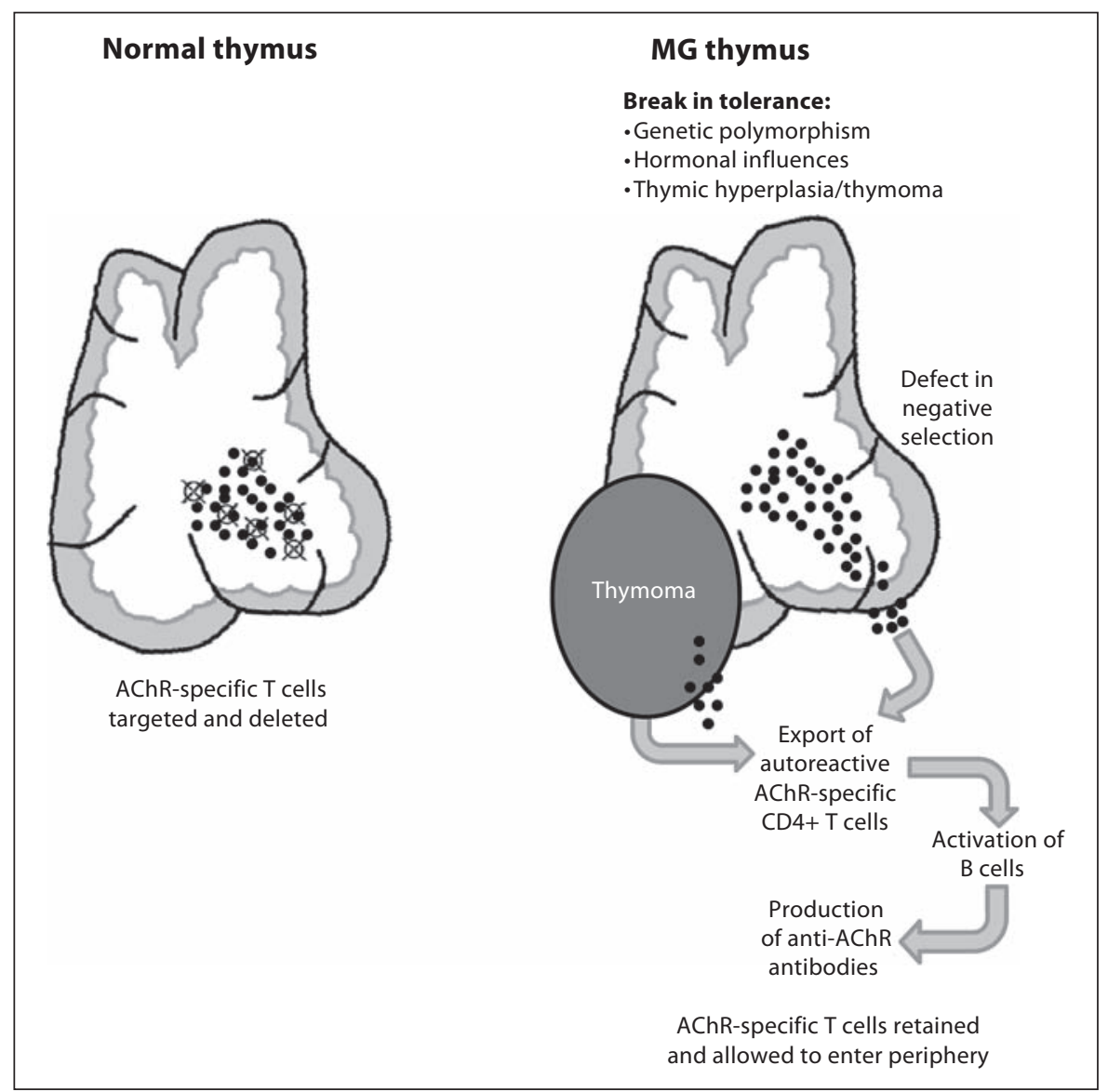

control of AIRE, which facilitates induction of apoptosis in potentially autoreactive T cells [15]. In addition, it promotes apoptosis of terminally mature medullary thymic epithelial cells to drive tolerogenic cross-priming by thymic dendritic cells. Expression of AIRE is absent in nearly $95 \%$ of thymomas, including those associated with MG [16], and it is clear that defective expression of AIRE favors thymic development of self-reactive $\mathrm{T}$ cell clones.

Another risk factor involved in MG onset is gender. Women exhibit greater incidence of MG than men, and pregnancy influences manifestation of disease $[17,18]$. This indicates a role for sex hormones, which is likely a direct effect since many immune cell populations - including $\mathrm{B}$ and $\mathrm{T}$ lymphocytes - express receptors for sex and other steroid hormones [19]. A number of studies implicate estrogen as a primary mediator of $\mathrm{MG}$ disease [20], although progesterone could also be involved [21]. Estrogen is known to modify both innate and adaptive immunity and can promote production of antibodies by $B$ lymphocytes as well as influence $\mathrm{T}_{\text {reg }}$ function [22]. At elevated concentrations, estrogen can enhance humoral immunity by inducing helper $\mathrm{T}$ cell $\left(\mathrm{T}_{\mathrm{H}}\right)$ responses. In an animal model of MG, estrogen was shown to be important for driving AChR-specific $\mathrm{T}_{\mathrm{H}}$ and subsequent production of anti-AChR antibodies - resulting in increased disease severity [23]. In addition, a separate study showed that factors produced in the thymic environment altered estrogen receptor expression, and expression was increased on thymocytes and peripheral blood $\mathrm{T}$ cells of MG patients [24].

\section{Biology of Disease}

The exact triggering sequence that leads to MG is unknown, although the involvement of the thymus and $\mathrm{T}$ cells is certain (fig. 1). The balance between CD4+ $\mathrm{T}_{\mathrm{H}}$ lymphocyte subsets $\left(\mathrm{T}_{\mathrm{H}} 1, \mathrm{~T}_{\mathrm{H}} 2, \mathrm{~T}_{\mathrm{H}} 17, \mathrm{~T}_{\text {reg }}\right)$ is key to effective immune responses and protection from disease [25], and dysregulated $\mathrm{T}_{\mathrm{H}}$ activity has been demonstrated in the pathogenesis of MG [26]. $\mathrm{T}_{\mathrm{H}} 1$ responses are important for clearing viral and intracellular bacterial infec- 
tions and have also been implicated in $\mathrm{MG}[27,28] ; \mathrm{T}_{\mathrm{H}} 17$ responses eliminate extracellular bacterial and fungal infections but are elevated in patients with other autoimmune diseases, such as multiple sclerosis [29]; and $\mathrm{T}_{\text {reg }}$ responses are important for shutting down immune responses, prevent immune-mediated tissue damage, and are reduced in many MG patients. Interestingly, the immunodominant region for $\mathrm{T}_{\mathrm{H}}$ sensitization is located on the $\alpha$-subunit of AChR, which is distinct from the region for anti-AChR antibody induction and the cholinergic binding site [30].

\section{The Neuromuscular Junction}

The NMJ serves as the point of communication between nerves and muscles. It functions to convert an electrical impulse to a chemical signal that initiate muscle contraction [31]. The NMJ is located between an autonomic nerve terminal that releases the neurotransmitter acetylcholine (ACh) and stimulates AChR on surfaces of muscle fibers - the neuron motor endplate: (a) the presynaptic region consists of the unmyelinated motor nerve ending where $\mathrm{ACh}$ is synthesized in the cytoplasm and stored in vesicles until an action potential arrives and initiates vesicle fusion and $\mathrm{ACh}$ release into the synaptic cleft - the space between the nerve terminus and muscle cell; (b) the postsynaptic membrane contains AChR on its surface to bind the ACh released by the nerve ending after it diffuses across the postsynaptic cleft. Transmembrane MuSK is expressed selectively by skeletal muscle cells and is colocalized with AChR in the postsynaptic membrane [32], and (c) Schwann cells cap the NMJ and basal lamina and are critical for junction maintenance [32]. The release of vesicular ACh is a calcium-dependent process, and calcium is obtained through voltage-gated $\mathrm{Ca}^{2+}$ channels on the depolarized nerve. Once ACh diffuses across the synaptic cleft, it interacts with AChR on the muscle membrane, and ion channels on the membrane open - initiating a local depolarization process called the endplate potential. In healthy NMJs, the endplate potential is significantly larger than the threshold for generating an action potential in a muscle fiber. The difference between the 2 activation requirements is the safety factor of neuromuscular transmission, which is significantly affected in MG [33]. The postsynaptic survival time of ACh is typically short since ACh is quickly hydrolyzed by acetylcholinesterase (AChE) at the postsynaptic membrane - releasing both acetate and choline.

In MG, physical changes occur at the NMJ. The synaptic cleft widens, there is a reduced number of AChR available, and the postsynaptic membrane is compromised with repeated targeting by the immune system [34]. Although the amount of ACh released with each nerve stimulus is quantitatively normal, the postsynaptic membrane is often severely altered. Autoantibodies targeted against AChR are a common characteristic of MG and can disrupt signaling at the NMJ using 3 distinct mechanisms, with the type of destruction depending on the specific autoantibodies involved. The first and most important of these is complement-mediated lysis of the postsynaptic membrane at the motor endplate [2]. Membranes become permanently altered with distortion and weakening of the sarcolemma. A change in membrane structure alters the number of available AChR on the membrane surface and reduces the number of voltage-gated sodium channels. This, consequently, increases the action potential threshold of the muscle fiber. Secondly, when divalent antiAChR antibodies are present, there is accelerated internalization and degradation of AChR caused by the crosslinking of AChR by IgG. Lastly, the binding site of AChR may be directly blocked by autoantibodies specific for the binding site or for another site that sterically alters the accessibility of the AChR binding site.

\section{Autoantibodies in $M G$}

The mammalian AChR consists of 4 subunits $(\alpha, \beta, \gamma$, $\delta$ ), and the $\alpha$-subunit has 2 isoforms. In adults, the pentameric receptor is comprised of $2 \alpha$-subunits and 1 each of the $\beta$-, $\gamma$ - and $\delta$-subunits. Each subunit contains $4 \alpha-$ helices (M1-M4) that span the membrane; however, the $\mathrm{N}$-terminal and C-terminal regions remain in the extracellular space [31]. One binding site for ACh is located on each $\alpha$-subunit, and the sequential binding of $2 \mathrm{ACh}$ molecules controls the opening of the AChR cation-selective channel [31]. The primary immunogenic region of AChR has been identified by serum antibody binding in samples from MG subjects $[31,35,36]$. It is located on the $\mathrm{N}$-terminal segment of the $\alpha$-subunit of AChR at positions that correspond to the extracellular domain of $\mathrm{AChR}$, an area prominently displayed and accessible for antibody binding [31]. Importantly, the immunogenic region of each $\alpha$-subunit is close to the ACh binding site. In the majority of MG patients (approx. 80\%), serum antibodies directed against $\mathrm{AChR}$ at the NMJ are present [2]. The remaining patients may also have anti-AChR antibodies but the affinity is too low to be detected $[37,38]$. Leite et al. [37] reported that in a group of MG patients who were seronegative for anti-AChR antibodies by conventional diagnostic assays, $66 \%$ had low-affinity antibodies that were able to bind AChR. 
Other autoantibodies have also been identified in MG patients. Approximately $10 \%$ of patients develop antibodies against MuSK, which interferes with the activity of AChR by blocking action potential in muscles and depleting the synapse of MuSK $[38,39]$; however, the exact mechanisms of action of anti-MuSK antibodies are not well defined. When Cole et al. [40] injected anti-MuSKpositive human IgG from MG patients into mice, MuSK was depleted from the postsynaptic membrane, which led to disassembly of postsynaptic AChR clusters, retraction of the nerve terminal and fatiguing muscle weakness. In patients with paraneoplastic MG, serum antibodies directed against the intracellular striated muscle proteins titin and ryanodine as well as ryanodine receptor (RyR) are often detectable [6]. Antibodies to titin and RyR are found in up to $95 \%$ of MG patients with thymoma and are often used to diagnose disease subtype [41]. In MG thymomas, genetic transcripts and immunogenic epitopes from both titin and ryanodine have been detected, and patients with antibodies against RyR are reported to have poorer MG outcomes and more aggressive thymomas [41].

\section{Treatment Strategies}

Therapy for MG patients focuses on long-term management of the disease, such as thymectomy and the use of steroids and nonsteroidal agents for chronic immunosuppression but also short-term management of acute exacerbations (MG crisis) with plasma exchange and intravenous immunoglobulin (IVIg). Targeted therapy for MG management includes AChE inhibitors that reduce degradation of $\mathrm{ACh}$ at the neurological synapse, thereby increasing the duration of ACh signaling. With the exception of cholinesterase inhibitors, traditional treatments for MG are nonspecific for the mechanisms of disease. Although therapeutically effective in many patients, responses to treatments vary widely and only alleviate some symptoms but with significant side effects.

\section{Thymectomy}

Surgical removal of the thymus is commonly recommended for MG patients that develop thymomas but is also performed in some patients within 2 years of diagnosis [41]. Because of the strong linkage between the thymus and disease, thymectomy would seem a reasonable treatment but is not always effective [42]. A wide range of outcomes has been observed following thymectomy; some patients (30-60\%) who do not develop thymomas are reported to have complete remission in the 2 years following thymectomy, while patients with thymomas and MG have fewer rates of complete remission (10-20\%) [41]. Those who develop thymomas are also more likely to experience more exacerbated disease $[2,41]$.

\section{Anti-Inflammatory Therapies}

Glucocorticoids (GCs) are produced in the adrenal glands following activation of the hypothalamic-pituitary-adrenal axis during a stress response, and GCs are commonly used in the treatment of many autoimmune/ inflammatory conditions. They bind to intracellular receptors to inhibit cytokine release and other activities of a variety of immune cells, including dendritic cells, granulocytes, and monocyte/macrophage populations as well as B and T lymphocytes. There have been several reports of the effects of GCs on B cell development, and they can induce $\mathrm{T}$ lymphocyte apoptosis and a shift in the cytokine pattern by $\mathrm{T}_{\mathrm{H}}$ to reduce inflammation [19]. The use of GCs was among the first treatment regimen for $M G$ and remains the most common immunotherapy for reducing symptoms [2]. GCs, such as prednisone, are a long-term therapeutic approach for MG and have been shown to reduce the number of circulating lymphocytes in serum to achieve improvement or remission of disease in the majority (approx. 75\%) of patients [43-45]. In ocular MG, evidence suggests that GC treatment may delay or stop the progression to other classes of MG. Unfortunately, GC treatment has a number of side effects, including hypertension, impaired glucose tolerance, osteoporosis, psychosis, cataracts and steroid myopathy [2]. This illustrates the need for other treatments to replace or augment chronic use of GCs.

Steroid treatments as an immunosuppressant are not always effective in some MG patients and warrant the use of agents. Results have been achieved using azathioprine (purine antimetabolite), which interferes with $\mathrm{T}$ and $\mathrm{B}$ lymphocyte proliferation. In retrospective studies, azathioprine was shown to be effective in $70-90 \%$ of $M G$ patients [2, 46, 47]; however, it can take several months (up to a year) for efficacy and is often used in combination with prednisone $[47,48]$. A similar nonsteroidal agent used in the treatment of MG is mycophenolate mofetil, which selectively blocks purine synthesis to suppress $\mathrm{T}$ and B cell proliferation. Cyclosporin and tacrolimus are also useful treatments because they inhibit $\mathrm{T}$ cell proliferation through disruption of calcineurin signaling and, thereby, block the synthesis of IL-2 and other cytokines important for CD4+ T cell function [2]. Some MG patients have high levels of serum antibodies directed 
against the RyR [6], and tacrolimus can act as both an immunosuppressive agent as well as enhance RyR-related sarcoplasmic calcium release. Studies have reported favorable effects when tacrolimus is used as a monotherapy and when used in combination with prednisolone [4951]. One study reported reduced levels of proinflammatory cytokines (IFN- $\gamma$, IL-2, IL-10, and IL-13) and lower numbers of activated $\mathrm{B}$ cells in patients undergoing combination therapy with tacrolimus for 24 weeks, in addition to reduction of steroid dosage (often used as a mark of success in combination therapy trials) in $74 \%$ of patients [51].

\section{Other Therapies}

$\mathrm{AChE}$ terminates the actions of $\mathrm{ACh}$; therefore, treatments aimed at blocking AChE activity increase the likelihood that ACh will interact with AChR and induce muscular activity. The AChE inhibitor pyridostigmine bromide inhibits hydrolytic cleavage of ACh and is the most common AChE inhibitor drug used for MG treatment. Excess doses of AChE inhibitors can block depolarization of the synapse and neuromuscular transmission, resulting in cholinergic overdose and increased muscle weakness. The use of these drugs also has side effects, including stomach cramps, diarrhea, vomiting, sweating, bradycardia, atrioventricular block, diaphoresis, and increased bronchial and nasal secretions $[5,33]$. Furthermore, patients with anti-MuSK antibodies may have poor tolerance to AChE inhibitor drugs; and if antibodies directed against AChR block ACh access to the receptor, AChE inhibitors have little impact. Although successful in some patients, AChE inhibitors typically do not provide sustained symptom relief nor slow disease progression [35].

Myasthenic crisis (short-term exacerbated disease) is a complication of MG defined as worsening of muscle weakness that results in respiratory failure and requires intubation and mechanical ventilation [52]. Management is similar for the different forms of MG and involves reducing the level of autoantibodies. Two common treatment strategies are used in conjunction with high doses of GCs for the management of myasthenic crisis. Plasma exchange is also used to deplete anti-AChR antibodies as well as other serum antibodies [52]. This can be an effective strategy, but repeated treatments reduce coagulation factors, can precipitate cardiac events and stroke, and are only effective for a few weeks [53]. IVIg treatment is similar to plasma exchange as a treatment for acute myasthenic crisis and has less severe side effects than plasma exchange - generally limited to fever, nausea, and head- ache [53-55]. IVIg neutralizes the blocking effects of antibodies to AChR and is also used to treat other autoimmune/inflammatory disorders and neuromuscular pathogenesis, including Guillain-Barré syndrome and multifocal motor neuropathy $[37,53-56]$.

\section{Conclusions/Future Directions}

Certain individuals are more susceptible to the breakdown of tolerance against endogenous proteins that leads to excessive inflammation and tissue damage following immune system activation - as occurs with the autoimmune disorder MG. Therefore, it is important to understand host factors that can contribute to increased risk. This includes deciphering the interplay between the neuroendocrine and immune systems to help in the development of strategies to reduce susceptibility and severity of disease. In this review, we discussed how disease develops in the different forms of MG; however, more studies are necessary to identify the specific mechanisms by which host factors modify immunity and break tolerance to disrupt transmission in the NMJ. Several lines of evidence indicate additional strategies that could be useful in ameliorating disease. This could include the use of soluble receptors to $\mathrm{ACh}$, which could serve as decoys in MG patients that have circulating anti-AChR antibodies. Other strategies might include treatments aimed at modifying thymus activity to re-establish tolerance against AChR, MuSK, the striated muscle proteins titin and ryanodine, or other NMJ targets in MG patients. These and other treatment modalities could be considered in combination with current therapies in an effort to ensure that patients with MG are able to control their disease and improve their quality of life.

\section{Acknowledgment}

The authors would like to thank Dr. Susan Kirschner for thought-provoking discussions that contributed to the successful completion of the manuscript. 


\section{References}

1 Carr AS, Cardwell CR, McCarron PO, McConville J: A systematic review of population based epidemiological studies in myasthenia gravis. BMC Neurol 2010;10:46.

$\checkmark 2$ Meriggioli MN, Sanders DB: Autoimmune myasthenia gravis: emerging clinical and biological heterogeneity. Lancet Neurol 2009; 8:475-490.

-3 Shelly S, Agmon-Levin N, Altman A, Shoenfeld Y: Thymoma and autoimmunity. Cell Mol Immunol 2011;8:199-202.

-4 Strobel P, Chuang WY, Chuvpilo S, Zettl A, Katzenberger T, Kalbacher H, Rieckmann P, Nix W, Schalke B, Gold R, Muller-Hermelink HK, Peterson P, Marx A: Common cellular and diverse genetic basis of thymomaassociated myasthenia gravis: role of MHC class II and AIRE genes and genetic polymorphisms. Ann NY Acad Sci 2008;1132: 143-156.

5 Meriggioli MN: Myasthenia gravis with anti-acetylcholine receptor antibodies. Front Neurol Neurosci 2009;26:94-108.

6 Skeie GO, Romi F: Paraneoplastic myasthenia gravis: immunological and clinical aspects. Eur J Neurol 2008;15:1029-1033.

$\checkmark 7$ Wen JC, Liu TC, Chen YH, Chen SF, Lin HC, Tsai WC: No increased risk of adverse pregnancy outcomes for women with myasthenia gravis: a nationwide population-based study. Eur J Neurol 2009;16:889-894.

$\checkmark 8$ Ferrero S, Esposito F, Biamonti M, Bentivoglio G, Ragni N: Myasthenia gravis during pregnancy. Expert Rev Neurother 2008;8: 979-988.

-9 Tellez-Zenteno JF, Hernandez-Ronquillo L, Salinas V, Estanol B, da Silva O: Myasthenia gravis and pregnancy: clinical implications and neonatal outcome. BMC Musculoskelet Disord 2004;5:42.

-10 Romi F, Skeie GO, Aarli JA, Gilhus NE: The severity of myasthenia gravis correlates with the serum concentration of titin and ryanodine receptor antibodies. Arch Neurol 2000; 57:1596-1600.

$\checkmark 11$ Bartoccioni E, Scuderi F, Augugliaro A, Chiatamone Ranieri S, Sauchelli D, Alboino P, Marino M, Evoli A: HLA class II allele analysis in MuSK-positive myasthenia gravis suggests a role for DQ5. Neurology 2009;72:195197.

-12 Deitiker PR, Oshima M, Smith RG, Mosier DR, Atassi MZ: Subtle differences in HLA DQ haplotype-associated presentation of AChR alpha-chain peptides may suffice to mediate myasthenia gravis. Autoimmunity 2006;39:277-288

-13 Vandiedonck C, Raffoux C, Eymard B, Tranchant C, Dulmet E, Krumeich S, Gajdos P, Garchon HJ: Association of HLA-A in autoimmune myasthenia gravis with thymoma. J Neuroimmunol 2009;210:120-123.
14 Giraud M, Taubert R, Vandiedonck C, Ke X, Levi-Strauss M, Pagani F, Baralle FE, Eymard B, Tranchant C, Gajdos P, Vincent A, Willcox N, Beeson D, Kyewski B, Garchon HJ: An IRF8-binding promoter variant and AIRE control CHRNA1 promiscuous expression in thymus. Nature 2007;448:934-937.

15 Abramson J, Giraud M, Benoist C, Mathis D: Aire's partners in the molecular control of immunological tolerance. Cell 2010;140: 123-135

16 Marx A, Hohenberger $\mathrm{P}$, Hoffmann $\mathrm{H}$, Pfannschmidt J, Schnabel P, Hofmann HS Wiebe K, Schalke B, Nix W, Gold R, Willcox N, Peterson P, Strobel P: The autoimmune regulator AIRE in thymoma biology: autoimmunity and beyond. J Thorac Oncol 2010; 5:S266-S272.

17 Whitacre CC: Sex differences in autoimmune disease. Nat Immunol 2001;2:777-780.

18 Djelmis J, Sostarko M, Mayer D, Ivanisevic M: Myasthenia gravis in pregnancy: report on 69 cases. Eur J Obstet Gynecol Reprod Biol 2002;104:21-25.

19 Butts CL, Sternberg EM: Neuroendocrine factors alter host defense by modulating immune function. Cell Immunol 2008;252:715.

20 Li Y, Xiao B, Xiao L, Zhang N, Yang H: Myasthenia gravis accompanied by premature ovarian failure and aggravation by estrogen. Intern Med 2010;49:611-613.

21 Leker RR, Karni A, Brenner T, Weidenfeld J, Abramsky O: Effects of sex hormones on experimental autoimmune myasthenia gravis. Eur J Neurol 2000;7:203-206.

22 Polanczyk MJ, Hopke C, Vandenbark AA, Offner H: Treg suppressive activity involves estrogen-dependent expression of programmed death-1 (PD-1). Int Immunol 2007; 19:337-343.

23 Delpy L, Douin-Echinard V, Garidou L, Bruand C, Saoudi A, Guery JC: Estrogen enhances susceptibility to experimental autoimmune myasthenia gravis by promoting type 1-polarized immune responses. J Immunol 2005; 175:5050-5057.

24 Nancy P, Berrih-Aknin S: Differential estrogen receptor expression in autoimmune myasthenia gravis. Endocrinology 2005;146: 2345-2353.

25 Zhu J, Paul WE: CD4 T cells: fates, functions, and faults. Blood 2008;112:1557-1569.

26 Protti MP, Manfredi AA, Straub C, Howard JF Jr, Conti-Tronconi BM: CD4+ T cell response to the human acetylcholine receptor alpha subunit in myasthenia gravis. A study with synthetic peptides. J Immunol 1990; 144:1276-1281.

27 Moiola L, Galbiati F, Martino G, Amadio S Brambilla E, Comi G, Vincent A, Grimaldi LM, Adorini L: IL-12 is involved in the induction of experimental autoimmune myasthenia gravis, an antibody-mediated disease. Eur J Immunol 1998;28:2487-2497.
28 Liu R, Hao J, Dayao CS, Shi FD, Campagnolo DI: T-bet deficiency decreases susceptibility to experimental myasthenia gravis. Exp Neurol 2009;220:366-373.

29 Hirota K, Duarte JH, Veldhoen M, Hornsby E, Li Y, Cua DJ, Ahlfors H, Wilhelm C, Tolaini M, Menzel U, Garefalaki A, Potocnik AJ, Stockinger B: Fate mapping of IL-17-producing $\mathrm{T}$ cells in inflammatory responses. Nat Immunol 2011;12:255-263.

30 Protti MP, Manfredi AA, Straub C, Howard JF Jr, Conti-Tronconi BM: Immunodominant regions for $\mathrm{T}$ helper-cell sensitization on the human nicotinic receptor alpha subunit in myasthenia gravis. Proc Natl Acad Sci USA 1990;87:7792-7796.

-31 Boonyapisit K, Kaminski HJ, Ruff RL: Disorders of neuromuscular junction ion channels. Am J Med 1999;106:97-113.

32 Hughes BW, Kusner LL, Kaminski HJ: Molecular architecture of the neuromuscular junction. Muscle Nerve 2006;33:445-461.

33 Mehndiratta MM, Pandey S, Kuntzer T: Acetylcholinesterase inhibitor treatment for myasthenia gravis. Cochrane Database Syst Rev 2011;2:CD006986.

-34 Angelini C: Diagnosis and management of autoimmune myasthenia gravis. Clin Drug Investig 2011;31:1-14.

35 Drachman DB: Myasthenia gravis. N Engl J Med 1994;330:1797-1810.

-36 Lindstrom JM, Seybold ME, Lennon VA, Whittingham S, Duane DD: Antibody to acetylcholine receptor in myasthenia gravis. Prevalence, clinical correlates, and diagnostic value. Neurology 1976;26:1054-1059.

37 Leite MI, Jacob S, Viegas S, Cossins J, Clover L, Morgan BP, Beeson D, Willcox N, Vincent A: IgG1 antibodies to acetylcholine receptors in 'seronegative' myasthenia gravis. Brain 2008;131:1940-1952.

>38 Vincent A, Leite MI, Farrugia ME, Jacob S, Viegas S, Shiraishi H, Benveniste O, Morgan BP, Hilton-Jones D, Newsom-Davis J, Beeson D, Willcox N: Myasthenia gravis seronegative for acetylcholine receptor antibodies. Ann NY Acad Sci 2008;1132:84-92.

-39 Ghazanfari N, Fernandez KJ, Murata Y, Morsch M, Ngo ST, Reddel SW, Noakes PG, Phillips WD: Muscle specific kinase: organiser of synaptic membrane domains. Int J Biochem Cell Biol 2011;43:295-298.

40 Cole RN, Ghazanfari N, Ngo ST, Gervasio OL, Reddel SW, Phillips WD: Patient autoantibodies deplete postsynaptic muscle-specific kinase leading to disassembly of the ACh receptor scaffold and myasthenia gravis in mice. J Physiol 2010;588:3217-3229.

41 Zielinski M: Management of myasthenic patients with thymoma. Thorac Surg Clin 2011; 21:47-57, vi. 
-42 Okumura M, Inoue M, Kadota Y, Hayashi A, Tokunaga T, Kusu T, Sawabata N, Shiono H: Biological implications of thymectomy for myasthenia gravis. Surg Today 2010;40:102107.

-43 Cosi V, Citterio A, Lombardi M, Piccolo G, Romani A, Erbetta A: Effectiveness of steroid treatment in myasthenia gravis: a retrospective study. Acta Neurol Scand 1991;84:33-39.

-44 Evoli A, Batocchi AP, Palmisani MT, Lo Monaco $\mathrm{M}$, Tonali P: Long-term results of corticosteroid therapy in patients with myasthenia gravis. Eur Neurol 1992;32:37-43.

-45 Pascuzzi RM, Coslett HB, Johns TR: Longterm corticosteroid treatment of myasthenia gravis: report of 116 patients. Ann Neurol 1984;15:291-298.

-46 Kuks JB, Djojoatmodjo S, Oosterhuis HJ: Azathioprine in myasthenia gravis: observations in 41 patients and a review of literature. Neuromuscul Disord 1991;1:423-431.
7 Mantegazza R, Antozzi C, Peluchetti D, Sghirlanzoni A, Cornelio F: Azathioprine as a single drug or in combination with steroids in the treatment of myasthenia gravis. J Neurol 1988;235:449-453.

48 Palace J, Newsom-Davis J, Lecky B: A randomized double-blind trial of prednisolone alone or with azathioprine in myasthenia gravis. Myasthenia gravis study group. Neurology 1998;50:1778-1783.

49 Minami N, Fujiki N, Doi S, Shima K, Niino M, Kikuchi S, Sasaki H: Five-year follow-up with low-dose tacrolimus in patients with myasthenia gravis. J Neurol Sci 2011;300:5962.

50 Hart IK, Sharshar T, Sathasivam S: Immunosuppressant drugs for myasthenia gravis. J Neurol Neurosurg Psychiatry 2009;80:5-6.

51 Zhao CB, Zhang X, Zhang H, Hu XQ, Lu JH, Lu CZ, Xiao BG: Clinical efficacy and immunological impact of tacrolimus in Chinese patients with generalized myasthenia gravis. Int Immunopharmacol 2011;11:519524.
52 Chaudhuri A, Behan PO: Myasthenic crisis. QJM 2009;102:97-107.

53 Gilhus NE: Neuromuscular disease: acute treatment for myasthenia gravis. Nat Rev Neurol 2011;7:132-134.

54 Mandawat A, Kaminski HJ, Cutter G, Katirji B, Alshekhlee A: Comparative analysis of therapeutic options used for myasthenia gravis. Ann Neurol 2010;68:797-805.

55 Gajdos P, Chevret S, Toyka K: Intravenous immunoglobulin for myasthenia gravis. Cochrane Database Syst Rev 2008; CD002277.

56 Araujo LM, Chauvineau A, Zhu R, Diem $\mathrm{S}$, Bourgeois EA, Levescot A, Huerre M, Gombert JM, Bayry J, Daeron M, Bruhns P, Kaveri SV, Herbelin A: Cutting edge: intravenous Ig inhibits invariant NKT cell-mediated allergic airway inflammation through Fc $\gamma$ RIIIA-dependent mechanisms. J Immunol 2011;186:3289-3293. 